\title{
BMJ Open Patients, clinicians and researchers working together to improve cardiovascular health: a qualitative study of barriers and priorities for patient-oriented research
}

\author{
Maria-Jose Santana (D) , ${ }^{1,2}$ Sandra Zelinsky, ${ }^{1}$ Sadia Ahmed (D) ,,2 \\ Chelsea Doktorchik, ${ }^{1}$ Matthew James, ${ }^{1,3}$ Stephen Wilton, ${ }^{1,3,4}$ Hude Quan, ${ }^{1,3}$ \\ Nicolas Fernandez, ${ }^{5}$ Todd Anderson, ${ }^{3,4}$ Sonia Butalia ${ }^{1,3}$
}

To cite: Santana M-J, Zelinsky S, Ahmed S, et al. Patients, clinicians and researchers working together to improve cardiovascular health: a qualitative study of barriers and priorities for patientoriented research. BMJ Open 2020;10:e031187. doi:10.1136/ bmjopen-2019-031187

- Prepublication history and additional material for this paper are available online. To view these files, please visit the journal online (http://dx.doi org/10.1136/bmjopen-2019031187).

Received 20 April 2019 Revised 09 December 2019 Accepted 14 January 2020

Check for updates

(C) Author(s) (or their employer(s)) 2020. Re-use permitted under CC BY-NC. No commercial re-use. See rights and permissions. Published by BMJ.

For numbered affiliations see end of article.

Correspondence to Dr Maria-Jose Santana; mjsantan@ucalgary.ca

\section{ABSTRACT}

Objectives The overall goal of this study is to identify priorities for cardiovascular (CV) health research that are important to patients and clinician-researchers. We brought together a group of CV patients and clinicianresearchers new to patient-oriented research (POR), to build a multidisciplinary POR team and form an advisory committee for the Libin Cardiovascular Institute of Alberta. Design This qualitative POR used a participatory health research paradigm to work with participants in eliciting their priorities. Therefore, participants were involved in priority setting, and analysis of findings. Participants also developed a plan for continued engagement to support POR in CV health research.

Setting Libin Cardiovascular Institute of Alberta, Cumming School of Medicine, University of Calgary, Canada.

Participants A total of 23 participants, including patients and family caregivers $(n=12)$ and clinician-researchers $(n=11)$.

Results Participants identified barriers and facilitators to POR in CV health (lack of awareness of POR and poor understanding on the role of patients) and 10 research priorities for improving CV health. The CV health research priorities include: (1) CV disease prediction and prevention, (2) access to CV care, (3) communication with providers, (4) use of eHealth technology, (5) patient experiences in healthcare, (6) patient engagement, (7) transitions and continuity of CV care, (8) integrated CV care, (9) development of structures for patient-to-patient support and (10) research on rare heart diseases.

Conclusions In this study, research priorities were identified by patients and clinician-researchers working together to improve CV health. Future research programme and projects will be developed to address these priorities. A key output of this study is the creation of the patient advisory council that will provide support and will work with clinician-researchers to improve CV health.

\section{INTRODUCTION}

The patient is the only constant in the journey of care, the person who experiences
Strengths and limitations of this study

- Patients and clinician-researchers identified barriers and facilitators to work as partners in health research.

- Patients worked together with clinicians-researchers to identify priorities for health research.

- This patient-oriented research used a participatory health research approach.

- Participant demographics (other than age, gender, cardiovascular condition) were not collected which may be a limitation.

both the processes and the outcomes of care. As users of the healthcare system, patients hold information that is vital for the improvement of delivery of care, system functions and health policies. Patient experience provides insights into patient needs, preferences and values which are valuable for organisational design and improvements. ${ }^{1}$ Patient-oriented research (POR) presents an important opportunity towards building a collaborative model that involves patients in research programme to improve health and healthcare. Specifically, POR is conducted in multidisciplinary teams, working in partnership with all relevant partners including patients, family members and clinicians-researchers. It focuses on identifying patient priorities and applying the learnings to improve health and healthcare. ${ }^{1-5}$

In the last few years, efforts have been made to support patient and public engagement in health research to and within the healthcare system. In the UK, there are two organisations, INVOLVE ${ }^{6}$ (https://www.involve. org.uk), a charity that supports research that involves patients and public in health 
research with the vision to democratise research as well as (invo.org.uk), a government-funded programme to support active public involvement in National Health Service, public health and social care research. In the USA, the Patient-Centered Outcomes Research Institute $^{7}$ is a non-governmental organisation (pcori.org) that supports and funds research to improve healthcare decisions for patients, caregivers, clinical specialists, employers, insurers and policy-makers. In Canada, the Strategy for Patient-Oriented Research $(\mathrm{SPOR})^{1}$ a coalition of federal, provincial and territorial partners focuses on including the patient voice into the research process and incorporated into healthcare policy and practice. In Canada, and in POR, the term 'patient' refers to an overarching term inclusive of individuals with personal experience of a health issue and informal caregivers, including family and friends. ${ }^{1}$

Cardiovascular (CV) disease is a leading cause of death of men and women in Canada and is associated with significant morbidity, disability and hospitalisations. ${ }^{8}$ The past three decades have seen the introduction and application of many therapies for the prevention and treatment of CV disease. ${ }^{8-11}$ However, the experiences and outcomes from the patients' perspective with CV disease remain to be optimised. ${ }^{12}{ }^{13}$ POR offers new promise to increase the relevance of research and ultimately improve CV health and care to patients. This opportunity to gain an understanding of what matters to patients and to learn how patients' priorities align with clinician-researchers in CV care could result in research and outcomes that are more relevant to both patients and clinicians. ${ }^{2-4}$

The ultimate goal of the study was to identify CV health priorities while building bidirectional POR partnerships in CV health and form an advisory council to support future POR at the Libin Cardiovascular Institute of Alberta. ${ }^{14}$

\section{METHODS}

\section{Study context}

This qualitative descriptive study used participatory health research ${ }^{15}$ as the paradigm that guides the research process in eliciting the top 10 research priorities for CV health. Participatory health research guides the approach to engage the participants in the study in working together, recognising the value of each person's contribution to generation of knowledge in a process that is practical, collaborative and empowering. ${ }^{16-18}$ By working together in identifying priorities, we collected our data and analysed it in a collaborative manner. Additionally, during the final step of this study, these identified priorities will be disseminated, by members of the working together group, to key stakeholders who could act on the research priorities and improve CV health.

This study was guided by the Canadian Institutes of Health Research (CIHR) SPOR Patient Engagement framework. ${ }^{1}$ The patient engagement framework was developed to support the design and conduct of POR projects, while establishing the structures to build partnerships with patients, clinicians and researchers, to work together in research.

We conducted a 2-day workshop (figure 1), co-designed and co-led by a patient-research partner (SZ), who is one of the trainers for the national CIHR SPOR Foundational Curriculum. ${ }^{1}$ The foundational curriculum teaches patients and researchers the concepts of POR, health research and team building so that they can work better together in a respectful and collaborative environment with researchers and policy-makers. The leadership of a patient-partner emphasised the important role that patients played in the workshop ensuring their voices were heard and addressing potential power differentials that may occur. Based on the SPOR foundational curriculum and participatory health research approach, ${ }^{16-18}$ we
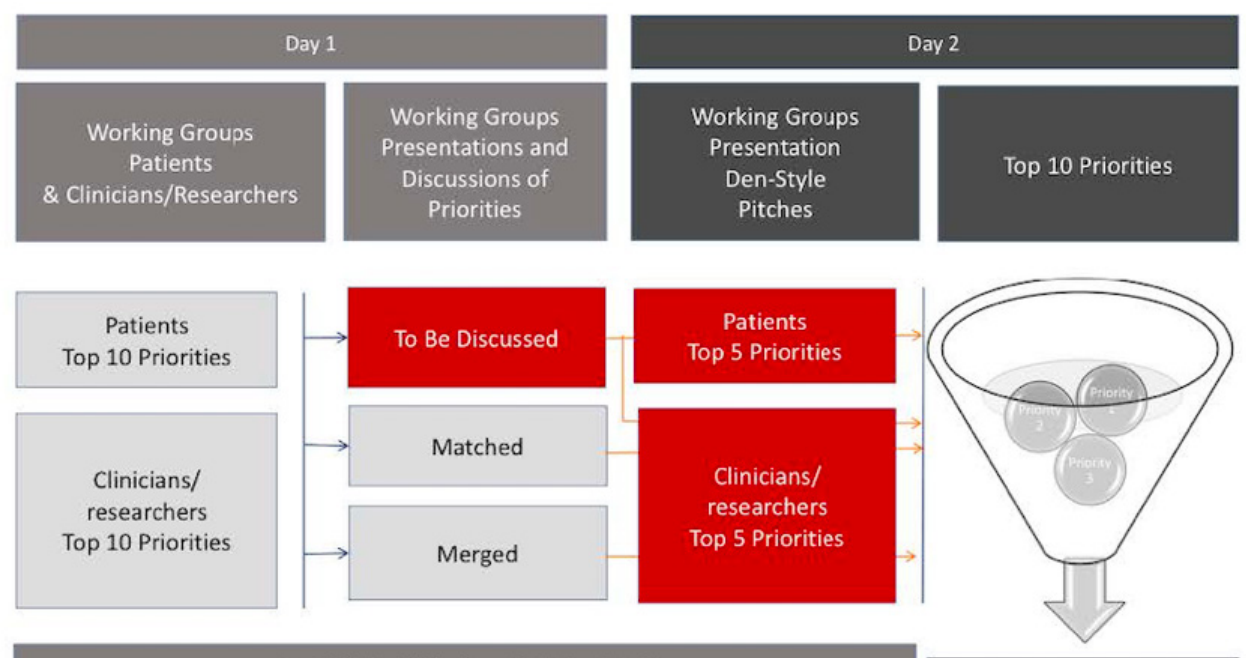

Feasibility Criteria - is it doable? Value - patient experiences, outcomes and cost

Figure 1 Overview of the study: identifying, refining and ranking the top 10 priorities. 
used a patient engagement process to guide the discussions and rank priorities (figure 1).

This workshop occurred at the Libin Cardiovascular Institute of Alberta in Calgary, ${ }^{14}$ Alberta in December 2017. The Institute serves and coordinates CV patient care, research and education for all of Southern Alberta, and Southeastern British Columbia (population of about 2 million). This Institute is affiliated with both the University of Calgary for academic activities and Alberta Health Services, the single provincial healthcare organisation.

\section{Sampling and participants}

Recruitment of patients: We strived for maximum variation including a diverse group of patients (diversity by age, sex, ethnicity, CV condition and disease stage, rural and urban residence). Recruitment flyers were shared with healthcare providers, clinic managers at outpatient clinics and tertiary healthcare centres in Alberta, and the patient engagement team at the provincial SPOR SUPPORT Unit. Patients who expressed interest in attending the workshop were then contacted by the lead patient research partner (SZ) to start the engagement process, discuss expectations and acquire consent. Informed, written consent was also obtained for both workshop days. The lead patient research partner (SZ) had no personal relationships with the participants. Patients were fully supported by ensuring that all out of pocket expenses were covered and an honorarium was provided as a recognition for their time and participation in the workshop.

Recruitment of clinicians and researchers: Clinicians and researchers from the Person to Population Cardiovascular Research Collaborative at the Libin Institute were invited to participate. This group was established with the Libin Institute with the goal of improving and optimising $\mathrm{CV}$ health in Alberta. This multidisciplinary team of researchers and clinician-researchers have expertise in patient-centred and family-centred care, health services research and CV care to catalyse POR priorities. A formal invitation to participate in this POR study was provided to the clinician-researchers accompanied by a brief description of the purpose and process of the workshop.

Theoretical framework: The theoretical principles guiding the development of this workshop are based on participatory health research, which aims to have the engagement of citizens, specifically patients and other stakeholders. The CIHR SPOR Patient Engagement framework ${ }^{1}$ helped in the development of the workshop by ensuring that patients are involved as equal partners throughout the research process. This framework is underpinned by four guiding principles of engaging patient in health research, including: (1) Inclusiveness, relates to integrating a diversity of patient perspectives. (2) Support, needs to be provided to patients to ensure meaningful discussions, establish safe environment and compensate financially for their work. (3) Mutual respect, as patients bring to the research their own experiences and expertise. When working together, strategies need to be developed to ensure that all partners value each other's expertise. (4)
Co-build, partnership develops as all individuals work together from the beginning to identify barriers and facilitators, set priorities for research and develop knowledge translation plans. The framework was presented to workshop participants, to set the stage for $\mathrm{POR}^{1}$ and build the foundation for working together.

Process: The workshop was co-designed and co-facilitated by POR experts; an academic researcher (MS) and patient research partner (SZ). This partnership helped to model and set the stage for participants to learn about POR, discuss potential barriers and facilitators to POR, identify top priorities for $\mathrm{CV}$ research, and work together on the development of a CV advisory committee. A participatory health research approach was used for involving all stakeholder partners in topic generation for POR $^{16-18}$ and was used to guide the discussions, vote and rank priorities. A plan to address disagreement was in placeany disagreements were discussed by the group until consensus was reached.

These discussions included diverse stakeholders and all participants contributed equally to the discussion. It included five steps:

1. Introduction to POR.

2. Identify barriers and facilitators to conducting POR.

3. Identify patient and clinician-researcher CV research priorities and vote on those priorities.

4. Presentations and discussions of top 10 priorities.

5. Discuss next steps to 'working together'.

To describe the process, we will refer to these five steps:

Step 1: On day one, the workshop started with the introductions of each participant using an ice-breaker to create a comfortable environment and encourage group cohesiveness. In addition, a set of rules on mutual respect and collaboration were presented to the group and displayed on the white board throughout the workshop. The co-facilitators (MS, SZ) provided a presentation introducing the group to POR using the CIHR framework on patient engagement. ${ }^{1}$ Specifically, there was an emphasis on the four guiding principles and the importance of everyone bringing valuable expertise to the working group. Additionally, the different levels of patient engagement using a modified version of the International Association for Public Participation Spectrum framework ${ }^{18}$ were presented. For instance, patients could be 'consulted' when the researcher seeks their input on ad-hoc basis, or patients could 'collaborate' in the research project as an equal partner and be a member of the research team. After the presentation, questions addressed points on power differentials, reinforcing the notion of co-building and mutual respect.

Step 2: Then participants were grouped in tables of five to discuss and document on flip chart papers the potential barriers and facilitators to conducting POR. This step was crucial in setting the stage for partnership building, as participants reflected on their concerns for POR, and how they could address those concerns. At each table, a volunteer served as chair to monitor discussions, ensuring everyone was heard, and another individual annotated 
the topics discussed and presented to the entire group for final discussions. Participants discussed how POR could be operationalised. As the discussions progressed, data were collected in large flip charts stuck to the walls. Then, after all the barriers and facilitators were identified by the group, the data collected were presented and discussed together to reach the final group of barriers and facilitators. Participants were encouraged to deal with disagreement while working in groups. In case of disagreement, discussion continued until agreement was achieved. This step led to the final identification of barriers and facilitators to POR in CV research.

Step 3: Participants were separated for a brainstorming activity to identify what CV research priorities mattered most to them. Clinician-researchers and patients were placed in separate groups for the initial brainstorming activity to allow participants to be comfortable in sharing their views and perspectives while identifying CV priorities. This allowed for each group to freely discuss and decide on CV priorities based on their expertise and experiences. Each table had a volunteer that chaired the discussions and another individual that presented the priorities to the larger group.

Flip charts were used to collect these data, and all together the priorities were analysed. In order to reach consensus from the 23 attendees, dotmocracy was used to narrow down to 10 priorities. ${ }^{19-21}$

Dotmocracy is a participatory large group decisionmaking tool. ${ }^{18-20}$ This tool has been used in priority setting, particularly with large groups (20-30 participants) as a method to recognise points of agreement. ${ }^{19-21}$ Dotmocracy was chosen as a prioritisation tool, as it has been used before with community members in other research projects of ours with success. This participatory tool engages patients in the research process, as partners in research. Dotmocracy allows participants to be fully engaged in the research process, especially if they have not participated in research before ${ }^{19-21}$ During this process, instructions were made clear to all participants to place one sticker per research priority, and each participant had a total of 10 stickers. The priorities with the least number of stickers were considered of lower priority. Then, the top 10 priorities were reviewed ensuring that the group felt that what was important to them, was addressed in the top 10 priorities. Before adjourning the meeting, a brief introduction to day 2 was provided.

Step 4: On day 2, patients and clinician-researchers worked together to co-create a short presentation focusing on the importance, relevance and feasibility of the chosen priorities. Ten teams including patient and clinicianresearchers co-presented one of the top 10 priorities as a 'pitch' that follow the 'Dragon's Den' format, and these presentations were video recorded with their consent.

This exercise enabled patients and clinician-researchers to work in partnership, co-designing and learning from one another. For example, some patients had difficulties in knowing the feasibility of conducting research for a specific priority. This provided the researcher an opportunity to help build their capacity by explaining the feasibility criteria, and the steps that would need to be taken in order to conduct the research.

Step 5: To conclude day 2 of the workshop, the top 10 priorities were presented back to the group for members checking. Then, the participants began to plan future steps, including the establishment of the advisory council to support future POR for CV health at the Libin Cardiovascular Institute of Alberta. ${ }^{14}$ The team worked also together in developing a communication strategy (eg, how to keep in contact), and establishing the degree of patient engagement. Finally, the team worked together in establishing a strategy to disseminate the findings of the study, evaluate progress and assess the impact of the advisory council on POR for CV health.

\section{Data collection}

Materials for data collection included notes, flip charts and videos. At the start of the workshop, barriers and facilitators to POR were written on flip charts and agreed on by all participants. Throughout the workshop two note-takers observed and collected discussion points to support discussions when needed. Then, discussions around the top 10 priorities were annotated onto the flip charts at each table, and later presented to the entire group. Dragon-style presentations (ie, pitches on priorities) were also video-taped.

\section{Data analysis}

The notes were thematically analysed by the research team (including patient-research partner) (SA, SZ, MS) to identify the top areas of prioritisation. A deductive process of identifying ideas and themes was done, followed by peer debriefing by the research team. Additionally, a summarised version of the top priorities was presented to the participants for member checking and further refinement. We then reviewed the notes and flip charts to ensure that no priorities were missed. After the workshop, video-taped presentations and flip charts were reviewed by two members of the team (SA, SZ) to confirm study findings. All notes and flip charts were stored in the principal investigator's office, and on password protected computers.

\section{Patient and public involvement}

This is a POR project; as such patients and a patientresearch partner were involved throughout different stages of the project (design conception, data collection, data analysis, dissemination).

\section{RESULTS}

A total of 23 participants attended the workshop. Twelve patients were invited, however due to time conflicts, two were unable to make it to the workshop. There were 10 individuals (patients) with CV conditions who participated in the workshop. They ranged in age from 35 to 70 years old, and $50 \%$ were women. Their CV conditions 
Table 1 Barriers and their associated solutions to patient-oriented research (POR) identified by patients and clinicianresearchers

\begin{tabular}{ll}
\hline Barriers to POR & Identified solutions \\
\hline Lack of awareness of the existence of POR & $\begin{array}{l}\text { Building networks with patient and family advisors. } \\
\text { Reaching out to communities. } \\
\text { Connecting with healthcare providers. } \\
\text { Using social media (eg, Facebook, Twitter). }\end{array}$ \\
$\begin{array}{ll}\text { Clear expectations and roles. } \\
\text { Lack of understanding of the role of patients - } \\
\text { where do patients fit into health research? }\end{array}$ & $\begin{array}{l}\text { Accommodating patient partners (ie, using technology such as email, } \\
\text { Access/opportunities to participation in POR } \\
\text { (distance, time) }\end{array}$ \\
$\begin{array}{l}\text { phone, etc. to allow for virtual meetings). } \\
\text { Diverse backgrounds }\end{array}$ & $\begin{array}{l}\text { Working together with a collaborative mindset. } \\
\text { Ensuring there is diversity (in education, ethnicity, age, working status, sex } \\
\text { and gender) in your team to incorporate multiple perspectives. }\end{array}$ \\
\hline
\end{tabular}

included coronary artery disease, arrhythmias, heart transplants and congenital heart disease. Two spouses (ages 65 to 70 years) also participated. Of the 12 patients and caregiver participants, 4 were from rural Alberta. We invited the core group of clinician-researchers of the P2 group (nine clinician researchers), however due to time conflicts, two were unable to join the workshop. The seven clinicians ( $3 / 7$ women) were physicians and nurses with specialties in $\mathrm{CV}$ care, endocrinology, nephrology and internal medicine. Four participants were health services researchers ( $3 / 4$ women). Of all the participants, there was diversity in ethnicity including participants of Latino, South Asian, Filipino, Chinese and Caucasian backgrounds.

Table 1 presents the barriers and solutions to POR discussed by all participants.

\section{Identifying research priorities}

As depicted in figure 1, participants worked independently in groups of patients and clinician-researchers to identify their top 10 priorities. Then all of these priorities were discussed and classified into three groups (displayed in figure 2), including five priorities from patients, five common priorities to both groups (matched) and three priorities unique to clinician-researchers. Then out of the other eight priorities, three were merged. Merged priorities included: patient experiences (from patients)



Figure 2 Priorities for CVD research identified by patients, caregivers and clinicians and researchers. CVD, cardiovascular disease. merged with patient-reported experiences and outcomes (from clinician-researchers) and three priorities (tool to support decision-making, technology to predict and prevent CV disease, and patient and caregivers' perceptions on the role of technology in patient engagement) merged into priority 4-e-health technology. Matched priorities emerged from discussions as common priorities to patients and clinician-researchers. These priorities were discussed and the top 10 were selected.

No disagreement was encountered throughout the workshop, as each priority was discussed among the group.

\section{The top $10 \mathrm{CV}$ research priorities}

Selected top priorities are presented in order of ranking in the following paragraphs; and summarised in online supplementary appendix 1 with selected quotes from participants to further illustrate the discussions that took place during the priority setting exercise. Furthermore, after the workshop clinician-researchers met and developed some questions to conduct future research based on these priorities, including 'How can we co-design tools with patients and caregivers to predict and communicate risk factors for cardiovascular disease?' (see online supplementary appendix 1). These questions were presented to the patient advisory council and have been used as research questions for grant proposals.

\section{Prevention and prediction}

Patients discussed that despite adhering to recommendations they had to prevent recurrent events, including heart attacks, they felt being provided with information on prevention was not enough. Participants identified research on prediction of future events important to better inform their conversations during clinical visits.

\section{Access to care}

Accessing after regular hours care, waiting to see specialists and access to care for patients living in rural communities were identified as patient priorities. Patients emphasised the importance of research focusing on providing care 
to underserved populations and improving quality of life and efficiency by addressing travel time for care.

\section{Communication}

Communication was highlighted as key to empowering patients to understand their condition, promote adherence to treatment and ultimately improve health outcomes. Participants highlighted the importance of building trust through communication, not only providing information but also by ensuring that the patients understand the information.

\section{e-Health technology}

The use of e-health technology was raised as a research priority by researchers, especially in the facilitation of communication between patients and healthcare providers.

\section{Patient experience}

The focus was on understanding what was important to patients, the measurement of patient experiences and the development of strategies to address the needs of patients and caregivers.

\section{Patient engagement}

Patient engagement was identified as a pillar to support disease management and promote decision-making while improving care and patient outcomes. Participants discussed empowerment strategies to enhance engagement, including sharing information and opportunities to use information tools available to both patients and clinicians.

\section{Transitions and continuity of care}

Participants highlight the need for research on strategies to improve transitions and test interventions that will improve continuity of care.

\section{Integrated care}

For patients, integrated care meant efficient and timely care, while for providers it implied safety and quality of care.

\section{Patient to-patient support}

Peer support was identified as a priority and an opportunity to learn and find support from individuals that have common lived experiences.

\section{Rare heart disease}

Patients wanted to become their own advocates and particularly access specialists and knowledge when they had rare heart diseases.

At the end of the workshop, participants agreed on creating a patient advisory council to work together with clinician-researchers to improve CV health. The newly created group planned to meet quarterly during the year to further develop the projects based on the identified priorities and to develop a plan to ensure future sustainability of the group, with the support of the Libin Institute $^{14}$ and through external funding sources (ie, grants).

\section{DISCUSSION}

This study described a Working Together workshop that included patients and clinician- researchers. This group co-developed CV research priorities at a Canadian academic CV health research institute. These priorities are important to inform provincial programme for CV research, funding priorities, grant proposals and research projects to ultimately improve CV health of patients and communities.

The theoretical principles guiding this workshop are of participatory health research, ${ }^{15-17}$ and underpinned in the four pillars of engaging patient in health research. ${ }^{1}$ Inclusiveness was addressed by recruiting participants with diverse backgrounds, including patients with different CV conditions and clinician-researchers with different specialties. The priorities identified could be used in generic CV research projects (from hypertension, diabetes, heart failure to kidney failure and congenital heart disease). Support was offered to patients from the beginning of the project through discussions on their expectations, establishing a safe environment and compensating them financially for their time working together. While establishing a safe environment, a set of rules were presented at the start of the workshop, emphasising mutual respect and ensuring that patients were equal partners in the process and all partners value each other expertise. Without creating the safe and collaborative environment, partnership will be difficult. Partnership is a key aspect of working together that was developed from the beginning throughout the workshop to identify barriers and facilitators, set priorities for research and co-build knowledge translation plans.

In CV health, Vandigo et $a l^{22}$ examined a hypothetical example on how patients could be engaged in CV health research. In contrast, in our study patients and clinicianresearchers worked together during the 2-day workshop. A patient-partner and an academic led the workshop. This leadership was strategic to ensure that patients felt represented and heard throughout the process. In addition, the leadership of a trained patient-partner reflected the high level of engagement described by the International Association for Public Participation, ${ }^{18}$ leveraging patient's involvement and leadership in research activities.

We found that our identified priorities had a strong emphasis on patient-centred care, as depicted in Santana et al framework ${ }^{23}$ including access to care, communication, improving patient experiences, patient engagement, transitions and continuity of care, and integration of care. The impact of patient-centred care in priority setting has been noted in previous studies. ${ }^{24-37}$ However, most of these studies identified priorities related to burden on symptoms and treatment, whereas in our study the priorities were related to more general challenges of healthcare. Our findings addressed healthcare system issues such as patient-provider communication, while patients in dialysis prioritised itchiness as a burdensome symptom.

In a hypertension management project, Khan et $a l^{27}$ found alignment with our results, as prevention and 
prediction was a top research priority. However, while Khan et al emphasised lifestyle interventions, our focus was on providing information to patients on how prevention strategies could predict another CV event. For instance, when patients follow all the prevention advice (lifestyle changes) that will predict the risk of preventing another heart attack. Moreover, Etchegary et $a t^{28}$ in a Canadian setting conducted public consultations revealing priorities that aligned with our findings, including access to care in rural areas and prevention and health promotion.

Recently, several approaches have emerged in an attempt to guide patient engagement. However, to date, there is no one formula on how to conduct POR. ${ }^{2-4} 17$ 22-38 The evidence is scarce on the process, best practices and evaluation of the engagement. ${ }^{24} 33$ Recent reviews revealed that patients are not meaningfully engaged. ${ }^{31-33}$ We framed the workshop according to the methods for engaging patients in topic generation for research, ranking priorities in a large group setting, and dotmocracy. Dotmocracy has been identified as one of the four methods for priority setting by Ontario Health. ${ }^{20}$ Other research priorities approaches includes the James Lind Alliance approach, ${ }^{37}$ specifically in developing research priorities for prostate cancer, ${ }^{35}$ hypertension management ${ }^{27}$ and gestational diabetes mellitus. ${ }^{34}$ Other approaches include the Delphi ${ }^{30}$ and the nominal group technique. ${ }^{36}$ Selection of methods depends on the purpose of the study, diversity and size of participants. A recent review by Manafo $e t a l^{8}$ described the levels of patient engagement in priority settings as tier 1 and tier 2, and highlight several ways to identify priorities emphasising that 'one-size doesn't fit all'. For the purposes of our workshop, dotmocracy was the best approach in engaging clinician-researchers and patients new to POR.

This study focused on including patients as partners in research, therefore demographics other than age, sex and $\mathrm{CV}$ condition were not collected. We acknowledge this as a potential study limitation. Another study limitation in conducting POR is related to the fact that the two groups (patient and clinician-researcher) are not accustomed to working together, and therefore it is possible that they inhibited or censored themselves in contributing their ideas. However, we tried to allow for the participants to know each other, starting with an 'ice-breaker' exercise, emphasising respect, partnership and providing time for patients to identify barriers and generate ideas in their own way. By working together in groups, patients and clinician-researchers were able to learn from each other, valuing their different perspectives. Participants were able to get an idea of what POR looks like, and how future partnerships can be developed. This workshop paved the way for a patient-advisory council at the Libin Institute, led by a patient who attended the workshop. Thus far, our patient partners have discussed the questions raised from the workshop and are working in research proposals to address some of these priorities. The patient advisory council is active, and we have managed to secure funding from the Libin Institute to ensure sustainability for the next 3 years.

\section{CONCLUSION}

This research project is one of the first Canadian studies identifying priorities in CV health. In this study, we have explored POR needs in Alberta for CV health research by engaging patients and clinician-researchers to establish a multidisciplinary team with an array of expertise and backgrounds. We also identified barriers to conduct POR and discussed solutions. A key output of this study is the creation of the patient advisory council that will provide support and will work with clinician-researchers to improve CV health. Finally, this study can inform the design of other POR projects and enlighten high priority areas for future $\mathrm{CV}$ health research that is relevant to patients.

\section{Author affiliations}

${ }^{1}$ Community Health Sciences, University of Calgary, Calgary, Alberta, Canada

${ }^{2}$ Pediatrics, University of Calgary, Calgary, AB, Canada

${ }^{3}$ Medicine, University of Calgary, Calgary, $A B$, Canada

${ }^{4}$ Cardiac Sciences, University of Calgary, Calgary, AB, Canada

${ }^{5}$ Family and Emergency Medicine, Université de Montréal, Montreal, Quebec, Canada

Twitter Maria-Jose Santana @MariaJ_Santana, Sadia Ahmed @SadiaAHSOC591 and Sonia Butalia @Sonia_ButaliaMD

Acknowledgements The authors thank all participants for their dedication and support to this patient-oriented research project. The authors appreciate comments from Kimberly Manalili and Paul Fairie.

Contributors MS is the principal investigator. $\mathrm{SZ}$ is the patient research partner. MS and SZ conceived the idea and drafted the initial manuscript. SA, CD, MTJ, SW, HQ, NF, TA, SB provided input on various drafts of the manuscript. All authors provided important intellectual contribution and guidance throughout the development of the manuscript. All of the authors (MS, SZ, SA, CD, MTJ, SW, HQ, NF, $\mathrm{TA}, \mathrm{SB}$ ) contributed to critical review and revisions to the manuscript, agreeing on the final version.

Funding This work was supported by the Canadian Institutes of Health Research Patient-Oriented Research Collaboration Grants (number 319191). Cumming School of Medicine at the University of Calgary, and Alberta Health Services' Diabetes, Obesity and Nutrition Strategic Clinical Network.

Competing interests None declared.

Patient consent for publication Not required.

Ethics approval The study was approved by the University of Calgary Conjoint Health Research Ethics Board, REB17-0864.

Provenance and peer review Not commissioned; externally peer reviewed.

Data availability statement All data relevant to the study are included in the article or uploaded as supplementary information. No additional data are available.

Open access This is an open access article distributed in accordance with the Creative Commons Attribution Non Commercial (CC BY-NC 4.0) license, which permits others to distribute, remix, adapt, build upon this work noncommercially, and license their derivative works on different terms, provided the original work is properly cited, appropriate credit is given, any changes made indicated, and the use is non-commercial. See: http://creativecommons.org/ licenses/by-nc/4.0/.

\section{ORCID iDs}

Maria-Jose Santana http://orcid.org/0000-0002-0202-5952

Sadia Ahmed http://orcid.org/0000-0002-8040-7198 


\section{REFERENCES}

1 Canadian Institutes of Health Research [Internet]. Canadian strategy for patient-oriented research (SPOR). Available: http://www.cihr-irsc. gc.ca/e/41204.html [Accessed 1 May 2018].

2 Domecq JP, Prutsky G, Elraiyah T, et al. Patient engagement in research: a systematic review. BMC Health Serv Res 2014;14:89.

3 Boivin A, Lehoux P, Lacombe R, et al. Involving patients in setting priorities for healthcare improvement: a cluster randomized trial. Implement Sci 2014;9:24.

4 Shippee ND, Domecq Garces JP, Prutsky Lopez GJ, et al. Patient and service user engagement in research: a systematic review and synthesized framework. Health Expect 2015;18:1151-66.

5 Valderas JM, Ricci-Cabello I, Prasopa-Plaizier N, et al. World Health organization technical series on safer primary care: patient engagement, 2016.

6 Hanley B, Bradburn J, Barnes M, et al. Involving the public in NHS public health and social care research: briefing notes for researchers. INVOLVE: Eastleight, 2004.

7 Forsythe LP, Ellis LE, Edmundson L, et al. Patient and stakeholder engagement in the PCORI pilot projects: description and lessons learned. J Gen Intern Med 2016;31:13-21.

8 Public Health Agency of Canada. Tracking heart disease and stroke in Canada, 2009. Available: www.phac-aspc.gc.ca [Accessed 23 May 2018].

9 Statistics Canada. Leading causes of death, by sex, 2015. Available: http://www.statcan.gc.ca/tables-tableaux/sum-som/I01/cst01/ hlth36a-eng.htm [Accessed Nov 2016].

10 Yusuf S, Sleight P, Pogue J, et al. Effects of an angiotensinconverting-enzyme inhibitor, ramipril, on cardiovascular events in high-risk patients. N Engl J Med 2000;342:145-53.

11 Heart Protection Study Collaborative Group. MRC/BHF Heart Protection Study of antioxidant vitamin supplementation in 20536 high-risk individuals: a randomised placebo-controlled trial. The Lancet 2002;360:23-33.

12 European Society of Cardiology. Available: https://www.escardio.org/ The-ESC/What-we-do/esc-patient-engagement

13 McClellan M, Brown N, Califf RM, et al. Call to action: urgent challenges in cardiovascular disease: a presidential Advisory from the American heart association. Circulation 2019;139:e44-54.

14 The Libin Cardiovascular Institute. Available: www.libin.ucalgary.ca [Accessed 12 May 2018].

15 Wright MT, Brito I, Cook T, et al. International collaboration for participatory health research; 2013. Position paper 1: what is participatory health research? Version: Mai. Berlin, 2013.

16 Haywood K, Brett J, Salek S, et al. Patient and public engagement in health-related quality of life and patient-reported outcomes research: what is important and why should we care? Findings from the first ISOQOL patient engagement symposium. Qual Life Res 2015;24:1069-76.

17 Marlett N, Shklarov S, Marshall D, et al. Building new roles and relationships in research: a model of patient engagement research. Qual Life Res 2015;24:1057-67.

18 The International Association for Public Participation [Internet]. Available: www.iap2.org [Accessed 10 Feb 2010].

19 Hidalgo ES. Dotmocracy and planning Poker for uncertainty management in Collaborative research: two examples of co-creation techniques derived from digital culture. Proceedings of the Sixth
International Conference on Technological Ecosystems for Enhancing Multiculturality, ACM, 2018.

20 Nv B, Thesenvitz J. Priority Setting - Four Methods for Getting to What's Important! Available: http://www.ohpe.ca/node/11169 [Accessed 1 May 2018]

21 Diceman J. Dotmocracy Handbook (version 2.2), 2010. Available: http://library.uniteddiversity.coop/Decision_Making_and_Democracy/ dotmocracy_handbook.pdf [Accessed 23 May 2018].

22 Vandigo J, Oloyede E, Aly A, et al. Continuous patient engagement in cardiovascular disease clinical comparative effectiveness research. Expert Rev Pharmacoecon Outcomes Res 2016;16:193-8.

23 Santana MJ, Manalili K, Jolley RJ, et al. How to practice personcentred care: a conceptual framework. Health Expectations 2018;21:429-40.

24 Nass P, Levine S, Yancy C, the Patient-Centered Outcomes Research Institute (PCORI), its Board of Governors or Methodology Committee. Methods for involving patients in topic generation for patient-centered comparative effectiveness research, an international perspective, 2012. Available: info@pcori.org

25 McGrath B, Lynch J, Coe B, et al. Collaborative national consensus and prioritisation of tracheostomy quality improvements in the United Kingdom. Br J Anaesth 2018;120:e27.

26 Barnieh L, Jun M, Laupacis A, et al. Determining research priorities through partnership with patients: an overview. Semin Dial 2015;28:141-6.

27 Khan N, Bacon SL, Khan S, et al. Hypertension management research priorities from patients, caregivers, and healthcare providers: a report from the hypertension Canada priority setting partnership group. J Clin Hypertens 2017;19:1063-9.

28 Etchegary H, Bishop L, Street C, et al. Engaging patients in health research: identifying research priorities through community town halls. BMC Health Serv Res 2017;17:192

29 van Middendorp JJ, Allison H, Cowan K. Spinal cord injury priority setting partnership. top ten research priorities for spinal cord injury. Lancet Neurol 2014;13:1167.

30 van Middendorp JJ, Allison HC, Ahuja S, et al. Top ten research priorities for spinal cord injury: the methodology and results of a British priority setting partnership. Spinal Cord 2016;54:341-6.

31 Stewart RJ, Caird J, Oliver K, et al. Patients' and clinicians' research priorities. Health Technol Assess 2011;14:439-48.

32 Duffett L, Duffy L. Patient engagement: what partnering with patient in research is all about. Thromb Res 2017;150:113-20.

33 Chalmers I, Glasziou P. Avoidable waste in the production and reporting of research evidence. Lancet 2009;374:86-9.

34 Rees SE, Chadha R, Donovan LE, et al. Engaging patients and clinicians in establishing research priorities for gestational diabetes mellitus. Can J Diabetes 2017;41:156-63.

35 Mcilfatrick SJ, Keeney S. Identifying cancer nursing research priorities using the Delphi technique. J Adv Nurs 2003;42:629-36.

36 Rankin NM, McGregor D, Butow PN, et al. Adapting the nominal group technique for priority setting of evidence-practice gaps in implementation science. BMC Med Res Methodol 2016;16:110.

37 The James Lind Alliance. Available: http://www.lindalliance.org [Accessed 15 May 2018].

38 Manafò E, Petermann L, Vandall-Walker V, et al. Patient and public engagement in priority setting: a systematic rapid review of the literature. PLoS One 2018;13:e0193579. 